\title{
REPRESENTACÕ̃ES E VIVÊNCIAS DA VIOLÊNCIA NA PERSPECTIVA DE USUÁRIAS DE UM CENTRO DE REFERÊNCIA NO ATENDIMENTO À MULHER
}

\author{
REPRESENTATIONS AND EXPERIENCES OF THE VIOLENCE FROM THE PERSPECTIVE OF USERS OF A \\ REFERENCE CENTER FOR ASSISTANCE TO WOMEN
}

\section{RESUMO}

Este artigo apresenta os resultados de uma pesquisa de metodologia mista, desenvolvida com usuárias de um Centro de Referência de Atendimento à Mulher (CRAM), localizado numa cidade de porte médio, no Estado do Paraná. O CRAM atende mulheres em situação de violência, assegurando-lhes o acesso às políticas públicas em defesa de seus direitos. O enfoque teórico-metodológico valeu-se dos estudos de gênero (SCOTT) e de representação na perspectiva psicossocial (MOSCOVICI). Objetivou-se conhecer as práticas e representações da violência doméstica a que as mulheres estiveram expostas. Quarenta questionários ficaram disponíveis no CRAM por um período de 30 dias. A equipe técnica ficou responsável por orientar as usuárias que aceitassem integrar o estudo e vinte mulheres acederam ao convite. A sistematização dos dados seguiu a análise de conteúdo (BARDIN) e evidenciou que a violência é frequente na vida dessas mulheres. Concluiu-se que agressões praticadas pelos parceiros íntimos é um elemento que desestabiliza a vida.

Palavras-chave: Gênero. Serviço socioassistencial. Política Nacional de Promoção da Saúde.

\begin{abstract}
This article presents the results of a mixed methodology research, developed with users of a Reference Center for Assistance to Women (CRAM), located in a medium-sized city in the State of Paraná. CRAM serves women in violent situations, ensuring them access to public policies in defense of their rights. The theoretical-methodological approach used gender studies (SCOTT, SAFFIOTTI) and representation in the psychosocial perspective (MOSCOVICI). The objective was to know the practices and representations of domestic violence to which women were exposed. Forty questionnaires were available at CRAM for a period of 30 days. The technical team was responsible for orienting users who agreed to participate in the study and twenty women accepted the invitation. The systematization of the data followed the content analysis (BARDIN) and showed that violence is frequent in

Tania M. G. da Silva

Programa de Pós-Graduação Strictu sensu em Promoção da Saúde do Centro Universitário de Maringá (Unicesumar). Bolsista produtividade em pesquisa do Instituto Cesumar de Ciência, Tecnologia e Inovação (ICETI). Brasil. E-mail: tania.gomes@unicesumar.edu.br

Letícia C. G. Lopes

Centro Universitário de Maringá (Unicesumar). Integrante do Instituto Cesumar de Ciência, Tecnologia e Inovação (ICETI). Brasil. E-mail: leticia.cabral.lop@gmail.com
\end{abstract}


the lives of these women. It was concluded that aggressions practiced by intimate partners is an element which destabilizes life.

Keywords: Gender. Social Assistance Service. National Health Promotion Policy

\section{Introdução}

A violência contra as mulheres é um dos temas fulcrais do pensamento feminista moderno e a busca de seu entendimento faz parte da epistemologia feminista (BLAY, 2019). Suas raízes encontram-se no sexismo, resultado das desigualdades de gênero que marcam as relações masculino/feminino e legitimam a superioridade masculina em diferentes temporalidades. $\mathrm{O}$ sexismo não é um sistema de opressão solitário (SILVA et al., 2019). Para Miller \& Macwan (2019), a violência é o resultado de um processo histórico que vitima mulheres independente de classe, raça/etnia, escolaridade, religião, geração, nacionalidade, entre outras características identitárias. Configura-se, no entendimento de Santos \& Irineu (2019), em um desrespeito aos direitos humanos, sendo capaz de produzir inúmeros agravos à saúde física e mental das pessoas que estão expostas às situações de violência.

A violência contra as mulheres ou violência de gênero, como tem sido chamada na contemporaneidade, tem caráter polissêmico, isto é, seu conceito é variável em diferentes tempos e culturas. Aqui, seguindo a Convenção Interamericana para Prevenir, Punir e Erradicar a Violência contra a Mulher (Convenção Interamericana, 1994), é entendida como qualquer ato ou conduta baseada no gênero que possa causar morte, algum tipo de dano ou sofrimento físico, sexual ou psicológico às mulheres, podendo ocorrer tanto na esfera pública quanto na privada.

Pensar a violência contra as mulheres na perspectiva de gênero significa desnaturalizá-la, entendendo-a como o resultado de uma aprendizagem cultural que construiu a ideia de que homens são agressivos e mulheres submissas por assim estar inscrito na biologia. Contrapondo-se a um essencialismo biológico limitador e preconceituoso que, desde os tempos mais longínquos, insistiu na inferioridade física, intelectual e moral das mulheres, o conceito de gênero desnudou o papel fundamental da cultura como um elemento criador dos sujeitos e dos corpos. Assim, a categoria gênero consiste em um processo de hierarquização primária em que indivíduos do sexo masculino são tidos como superiores desde os primeiros instantes da vida, estabelecendo relações hierárquicas de poder (SCOTT, 1995), acabando por transformar a violência em "ato normal e corriqueiro, ao qual as pessoas não atribuem questionamentos, tornando-se invisível aos olhos dos que não querem enxergar, autovalorizando assim a sua ocorrência" (GOMES et al., 2018: 132).

A violência de gênero se manifesta em diferentes formas: física, psicológica, sexual, moral e patrimonial, apresentando ainda subtipologias: espancamentos, 
estupros, assédios, humilhações, xingamentos, controle financeiro, cyberbullying, tráfico humano, entre outras aviltações que podem, inclusive, levar à morte (BECCHERI-CORTEZ \& SOUZA, 2013). Embora os homens também sofram violência e até morram mais do que as mulheres em função dela, quando a análise leva em conta o pertencimento de gênero, as mulheres compõem o grupo de maior risco (GIANNINI \& COELHO, 2020; MINAYO \& SCHENKER , 2018).

Em torno de $35 \%$ das mulheres no mundo já sofreram algum episódio de violência e parte considerável dessas agressões ocorreu no próprio domicílio, sendo as mulheres das regiões mais pobres as mais vulneráveis (WHO, 2016). A América Latina apresenta um percentual alto de violência de gênero, incluindo aqueles com desfecho fatal: cerca de $65 \%$ dos assassinatos na região ocorrem no Brasil, Colômbia e México; de 2015 a 2018, nos três países, foram registradas 1.223.968 ocorrências de violência física contra mulheres (GIANNINI \& COELHO, 2020).

O Brasil é o quinto país no mundo onde mais ocorrem mortes de mulheres em função do pertencimento ao sexo feminino, chamada de feminicídio ou femicídio (GOMES, 2018). Apesar da Lei 13.104/2015, em 2017 foram registrados 1.133 feminicídios no país, cerca de $40 \%$ deles praticados por parceiros íntimos, incluindo aqueles com os quais as mulheres agredidas já não mantinham relacionamento. No mesmo ano, foram registrados mais de 221 mil casos de agressão, em decorrência de violência doméstica (lesão corporal dolosa), totalizando, assim, 606 casos por dia. A taxa de violência sexual é igualmente preocupante no Brasil, com registros de 60.018 casos de estupro, o que corresponde a uma média de 164 estupros por dia ou um a cada 10 minutos em 2017 (Atlas da Violência, 2019).

Conquanto se saiba que, no Brasil, a violência contra as mulheres é um problema de grande magnitude, sua análise requer atenção aos contornos regionais. O Paraná, por exemplo, apresenta índices superiores à média nacional: um caso de feminicídio a cada 24 minutos, ocupando a $20^{\text {a }}$ colocação em taxas de homicídios por 100 mil mulheres nas unidades da federação. Em 2017, o estado registrou 247 mortes de mulheres (Atlas da Violência, 2019) e 4.952 denúncias de estupro (Brasil, 2018). De janeiro a junho de 2017, foram notificados um total de 26.228 casos de violência doméstica no Paraná; embora esses números se refiram a ambos os sexos, as autoridades paranaenses reconheceram que as mulheres estiveram mais vulneráveis (FREIRE, 2019).

O presente estudo objetivou perceber as representações e conhecer as vivências de violência de gênero de mulheres atendidas em um Centro de Referência de Atendimento à Mulher (CRAM), em uma cidade de porte médio do Paraná.

O CRAM oferece atendimento e acompanhamento social, psicológico e orientação jurídica às mulheres em situação de violência, assegurando-lhes o acesso às políticas públicas em defesa de seus direitos. Argumenta-se, nesse artigo, que a violência de gênero se configura como uma violação dos direitos humanos, comprometendo de maneira decisiva a saúde e a qualidade de vida das mulheres. 


\section{Material e método}

Estudo de abordagem mista, realizada por meio de questionários entregues à diretoria do CRAM para serem aplicados pelas psicólogas e assistentes sociais às usuárias que aceitassem integrar a pesquisa. $\mathrm{O}$ critério de inclusão foi ser do sexo feminino, residente no município, ainda que de maneira temporária ${ }^{1}$, e ser usuária dos serviços. Os questionários foram aplicados na sede do CRAM, individualmente e em privacidade. Ele foi composto por 24 questões de múltipla escolha e por 2 perguntas abertas e opcionais.

As perguntas de número 1 a 7 referiam-se às condições socioeconômicas e sociodemográficas; as de número 8 a 23 apresentavam às entrevistadas situações de violência às quais elas podiam se identificar ou não, a partir das seguintes proposições: "me representa completamente", "me representa parcialmente" ou "não me representa”; a questão 24 analisava os tipos de violências já vividos. Por fim, as questões 25 e 26 , abertas e opcionais, visavam conhecer as representações e perscrutar, por meio de respostas mais subjetivas, suas experiências.

O exame dos dados seguiu a análise de conteúdo de Bardin (2016), tomando como suporte teórico a análise discursiva das representações sociais. Foram seguidos todos os procedimentos legais, como a assinatura do Termo de Compromisso Livre e Esclarecido, além do comprometimento de total anonimato. A pesquisa recebeu aprovação do Comitê de Ética em Pesquisa, em abril de 2019.

\section{Resultado}

Um total de 20 mulheres aceitou o convite e respondeu aos questionários disponibilizados no CRAM. Integraram o estudo aquelas que procuraram o serviço no período de 02 de maio a 30 de junho de 2019. A idade das participantes variou dos 17 aos 57 anos, correspondendo a uma média de 38,2 anos, sendo que 50\% da amostra estavam na faixa dos 30 aos 40 anos. No tocante à região de procedência das mulheres, o CRAM atendeu desde moradoras das zonas periféricas até aquelas que habitam o centro da cidade. A violência apareceu como parte da vida das integrantes da pesquisa e $85 \%$ delas tinham informações precisas sobre o Disque 18o, serviço de atendimento governamental para atender casos de violência contra as mulheres, em caráter sigiloso.

Um olhar sobre o Gráfico 1 aponta que a pesquisa trabalhou com mulheres que possuíam níveis de formação que lhes asseguravam condições mínimas de compreensão de seus direitos de cidadania: 40\% delas tinham curso superior

1 Algumas mulheres que frequentam o CRAM são moradoras de cidades vizinhas e, em função da violência doméstica, ficam temporariamente hospedadas nas casas-abrigo da cidade em que foi desenvolvida a pesquisa. 
completo e mais de $20 \%$ haviam concluído o ensino médio; considerando-se como integrantes desse grupo também as que não concluíram o ensino superior.

Gráfico 1 - Grau de escolaridade das entrevistadas

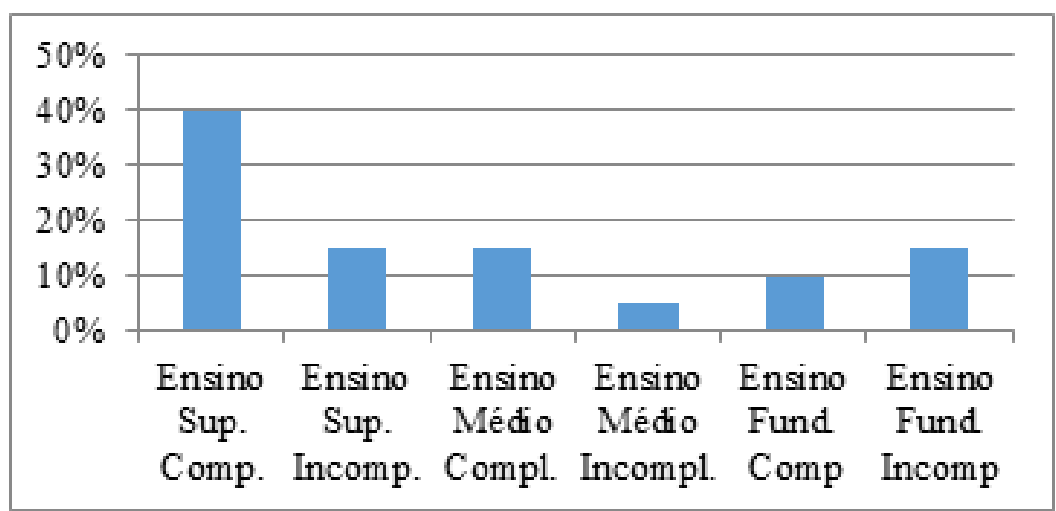

Fonte: Dados da Pesquisa

O Gráfico 2 apresenta a situação conjugal das mulheres no momento das entrevistas. Percebe-se que as solteiras sofreram mais violência do que as mulheres que viviam em união estável (sem oficialização civil) e as casadas. O quesito "outros" refere-se a mulheres que tinham namorados ou estavam vivendo relacionamentos abertos com mais de um parceiro.

Gráfico 2 - Situação conjugal das entrevistadas

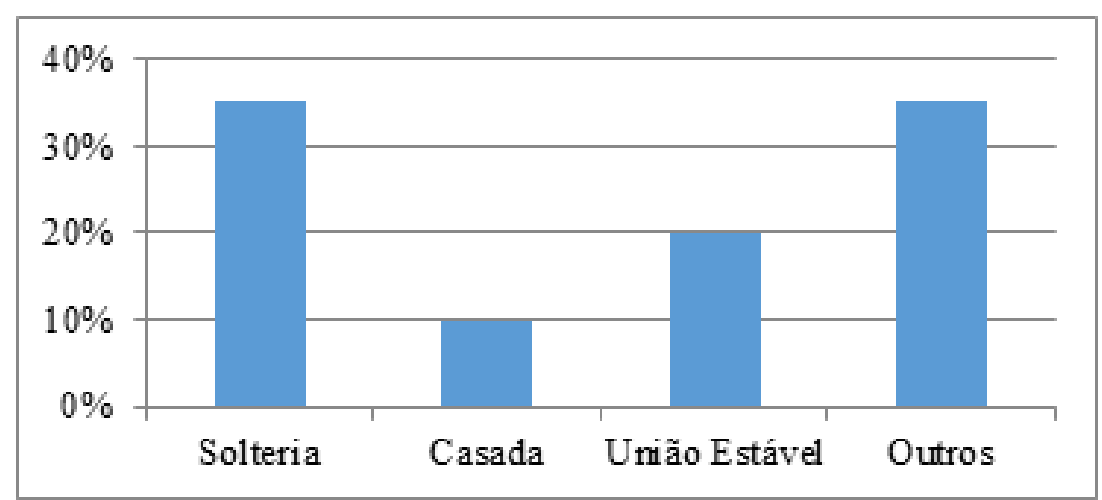

Fonte: Dados da Pesquisa

No Gráfico 3, verifica-se que entre as mulheres que sofreram violência predominaram as evangélicas, seguidas das católicas. As evangélicas tiveram 20\% a mais de casos de violência do que as católicas. O menor índice foi o das que se declararam seguidoras do Espiritismo. 
Gráfico 3 - Religião das entrevistadas

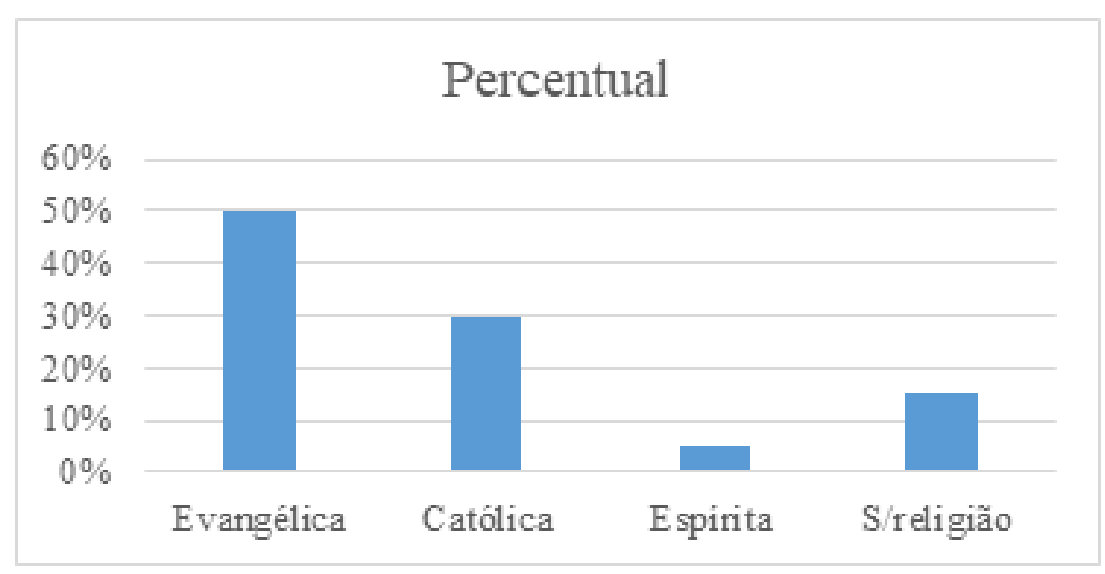

Fonte: Dados da Pesquisa

Percebe-se, a partir da análise do Gráfico 4, que as mulheres com menor poder aquisitivo, com ganho mensal de $\mathrm{R} \$ \mathbf{1 . 6 2 4}$, oo ou menos, integrantes da classe D e E, sofreram quase 50\% mais situações de violência doméstica do que aquelas de maior poder econômico: entre $\mathrm{R} \$ 9.254,00$ a $20.887,00$ mensais, integrando a classe B. Já mulheres inseridas na classe $C$, com rendimento mensal entre R \$1.625,00 e R \$ 9.253,00 mensais tiveram um índice de violência muito superior às mulheres do estrato $\mathrm{B}$, mas com menos de $10 \%$ do estrato D e E. A renda acima de $\mathrm{R} \$ 20.888$, oo caracteriza o estrato $\mathrm{A}$, porém não havia entre as entrevistadas nenhuma representante desse grupo. Os dados referentes aos valores que qualificam cada estrato foram buscados no Critério de Classificação Econômica da Associação Brasileira de Empresas e Pesquisa - ABEP (2016).

Gráfico 4 - Classe econômica das entrevistadas

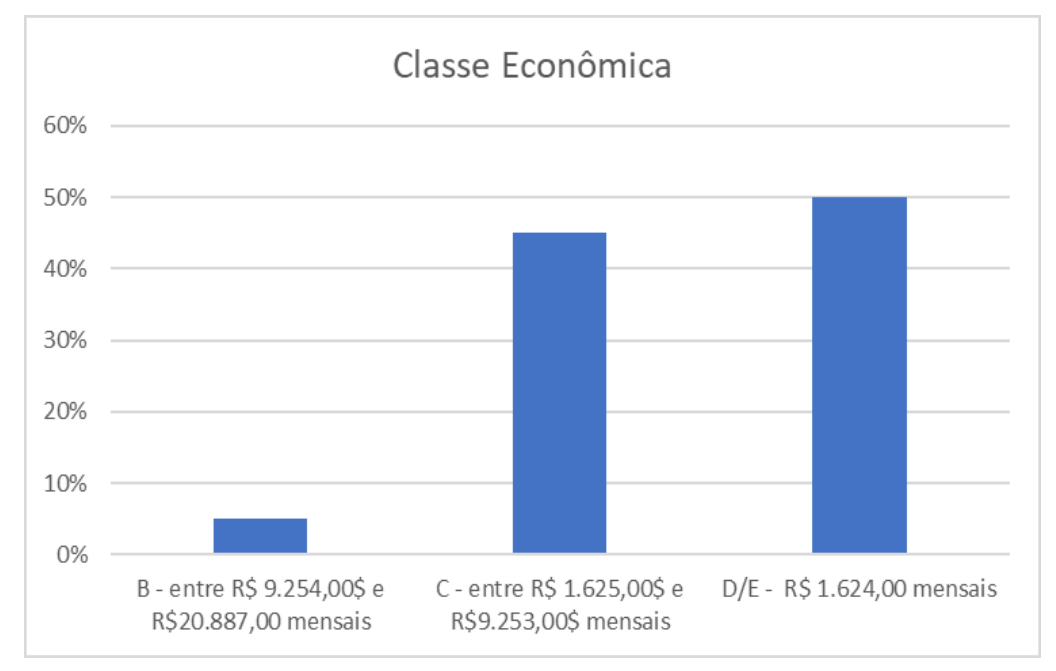

Fonte: Dados da Pesquisa 
As respostas às perguntas de caráter aberto possibilitaram o entendimento de que as mulheres têm uma compreensão clara do que seja a violência, não a circunscrevendo às agressões físicas. Quanto à forma de violência sofrida, houve uma sobreposição, isso é, as agressões ocorreram tanto por meio de abusos físicos quanto psicológicos.

Quadro 1 - Representações e práticas da violência de gênero

\begin{tabular}{|c|c|c|c|}
\hline Afirmativas & $\begin{array}{c}\text { Me representa } \\
\text { completamente }\end{array}$ & $\begin{array}{c}\text { Me representa } \\
\text { parcialmente }\end{array}$ & $\begin{array}{c}\text { Não me } \\
\text { representa }\end{array}$ \\
\hline $\begin{array}{l}\text { "Meu companheiro(a) já me inferiorizou em } \\
\text { ambiente público ou privado com frases como } \\
\text { "você é burra". }\end{array}$ & $45 \%$ & $30 \%$ & $25 \%$ \\
\hline $\begin{array}{l}\text { "Já ouvi frases como "você não sabe fazer nada } \\
\text { direito". }\end{array}$ & $50 \%$ & $40 \%$ & $10 \%$ \\
\hline $\begin{array}{l}\text { "Meu companheiro(a) já disse que meus } \\
\text { amigos e minha família "não prestam". }\end{array}$ & $70 \%$ & $30 \%$ & o\% \\
\hline $\begin{array}{l}\text { "Já fui direcionada por palavras similares à } \\
\text { "vadia". }\end{array}$ & $60 \%$ & $25 \%$ & $15 \%$ \\
\hline $\begin{array}{l}\text { "Estou sempre pedindo desculpas ao meu } \\
\text { parceiro(a)". }\end{array}$ & $30 \%$ & $30 \%$ & $40 \%$ \\
\hline $\begin{array}{l}\text { "Meu companheiro(a) exige ter acesso ao meu } \\
\text { celular sempre que deseja". }\end{array}$ & $60 \%$ & $15 \%$ & $25 \%$ \\
\hline $\begin{array}{l}\text { "Meu companheiro(a) já me proibiu (direta } \\
\text { e indiretamente) de ver/sair com amigos e } \\
\text { familiares". }\end{array}$ & $45 \%$ & $45 \%$ & $10 \%$ \\
\hline $\begin{array}{l}\text { "Meu companheiro(a) já pediu para que eu } \\
\text { trocasse a roupa que estava usando para ir a } \\
\text { algum local". }\end{array}$ & $35 \%$ & $25 \%$ & $40 \%$ \\
\hline $\begin{array}{l}\text { "Já me senti pressionada a realizar atos } \\
\text { sexuais dos quais eu não queria". }\end{array}$ & $45 \%$ & $25 \%$ & $30 \%$ \\
\hline $\begin{array}{l}\text { "Já tive meu salário controlado contra a minha } \\
\text { vontade". }\end{array}$ & $55 \%$ & $10 \%$ & $35 \%$ \\
\hline $\begin{array}{l}\text { "Meus documentos pessoais (como RG, CPF, } \\
\text { CNH) já foram escondidos de mim". }\end{array}$ & $10 \%$ & $15 \%$ & $75 \%$ \\
\hline $\begin{array}{l}\text { "Meus objetos pessoais (independente da } \\
\text { categoria) já foram quebrados por motivos de } \\
\text { brigas/discussões". }\end{array}$ & $60 \%$ & $30 \%$ & $10 \%$ \\
\hline $\begin{array}{l}\text { "Já recebi murros, tapas, apertões e/ou já } \\
\text { atiraram objetos em mim". }\end{array}$ & $70 \%$ & $15 \%$ & $15 \%$ \\
\hline "Eu me considero feminista". & $30 \%$ & $25 \%$ & $45 \%$ \\
\hline $\begin{array}{l}\text { "Eu sofro e/ou já sofri algum tipo de } \\
\text { violência". }\end{array}$ & $70 \%$ & $25 \%$ & $5 \%$ \\
\hline $\begin{array}{l}\text { "Eu estou ciente no número que devo ligar } \\
\text { para denunciar a violência". }\end{array}$ & $85 \%$ & $10 \%$ & $5 \%$ \\
\hline
\end{tabular}

Fonte: Dados da pesquisa 


\section{Discussão e análise}

Na maioria das sociedades contemporâneas, o modelo de gênero prevalente organiza e distribui feminilidades e masculinidades em termos de expectativas que validam o papel de agressores para os homens e exige das mulheres aceitação e passividade (GONÇALVES \& MELLO, 2017). Sob esta perspectiva, no Brasil e no mundo, assiste-se a valiosos esforços na busca do enfrentamento da violência contra as mulheres, contudo o fenômeno persiste e ainda está presente em todas as sociedades, atingindo países desenvolvidos e em desenvolvimento (SILVA et al., 2019 b).

Exemplo recente tem sido evidenciado pela COVID-19, que desnudou uma epidemia silenciosa: a violência contra as mulheres. Diante do elevado número de mortos pelo Coronavírus, a Organização Mundial da Saúde propôs o isolamento social (WHO, 2020). O isolamento social é uma forma de inibir a transmissão entre humanos, desacelerar o contágio e, consequentemente, diminuir e/ou postergar o pico da curva epidêmica (GARCIA \& DUARTE, 2020). Com os homens mais tempo dentro de casa, osíndices de violência doméstica aumentaram. Na China, as denúncias triplicaram desde os primeiros meses do confinamento e há relatos de aumento nas denúncias de agressões às mulheres na Itália, França, Espanha (VIEIRA, GARCIA \& MACIEL, 2020), Austrália, Brasil e Estados Unidos (PETERMAN et al., 2020). No Brasil, de primeiro a 25 de março, a Central de Atendimento à Mulher (Disque 180) recebeu 18\% mais ligações de denúncias e 990\% delas se relacionavam à situação de isolamento devido à pandemia (VIEIRA, GARCIA \& MACIEL, 2020). Conclui-se que as mulheres não estão seguras em seus domicílios, conforme ratifica a pesquisa empírica aqui apresentada.

O grau de escolaridade tem sido um quesito importante para a compreensão dos casos de violência contra mulheres. A maioria das mulheres que compôs o estudo tinha o curso superior completo, evidenciando resultado contrário à recente pesquisa realizada pelo Fórum Brasileiro de Segurança Pública e Instituto Data Folha, conduzida por Neme e Sobral (2019), onde se afirma que mulheres com escolarização mais alta procuram menos ajuda. Essa aparente discordância pode ser entendida tomando-se como princípio que, no Brasil, embora seja evidente o crescimento do número de mulheres nos cursos de graduação, há uma predominância delas em cursos menos valorizados, que as mantêm em condição de dependência (RICOLDI \& ARTES, 2016).

A segregação das mulheres em cursos de graduação menos valorizados traz inevitáveis reflexos sobre a vida profissional. O estudo de Ricoldi e Artes (2016) aponta que, na vida profissional, os homens ocupam mais os cargos de chefia, enquanto as mulheres predominam nos níveis mais baixos, nos quais, consequentemente, obtêm menores salários. Seguindo o mesmo entendimento, Vieira et al. (2019), exemplificam com os cursos de graduação em medicina e engenharias, afirmando que estes são constituídos majoritariamente por homens e a maioria dos estudantes é procedente 
de famílias de maior poder aquisitivo. Já na área da saúde, que não abrange a medicina, onde a remuneração é menor, predominam mulheres e integrantes de classes sociais mais baixas.

Contudo, se ter um diploma pode não significar a independência e a estabilidade financeira de uma mulher, por outro lado, ter maior escolaridade contribui para que elas negociem melhor seus direitos nas relações conjugais, porque geralmente têm uma profissão e dependem menos financeiramente de seus maridos, enquanto as mulheres de menor poder cultural e econômico são mais vulneráveis à violência, notadamente as que têm filhos (CRUZ \& IRFFI, 2019).

Quanto à análise da situação conjugal, percebeu-se que as mulheres solteiras e as que vivem uniões livres e esporádicas foram as que mais procuraram o CRAM para denúncias de violência por parte dos homens. Fiorotti et al. (2018) destacaram que não ter um companheiro fixo pode estar associado à violência por parceiro íntimo, visto que a existência de valores em comum comungados pelos parceiros em uma união conjugal e o comprometimento com a formação de uma família agiriam como efeitos protetores de um relacionamento.

Pode ainda ser que, numa sociedade estruturalmente misógina, haja maior rejeição às mulheres solteiras por se comportarem de maneira mais livre. A liberdade feminina pode fazer com que os homens se sintam ameaçados e, por isso, sejam mais agressivos. Mulheres vivendo uniões estáveis, isto é, sem oficialização legal e/ou religiosa da conjugalidade, também procuraram o CRAM para denúncias de violência.

Verificou-se que as mulheres casadas foram as que menos procuraram o CRAM para relatar abusos nos relacionamentos. Pode ser que mulheres casadas, ou seja aquelas que vivem em uma união legalizada, tenham mais dificuldades do que as que vivem em uniões livres ou estáveis para denunciar seus companheiros, por persistir no imaginário a representação de que elas integram, de fato, uma família ideal. Nesse caso, a denúncia agiria como um elemento demolidor dessa crença. Observe-se que, no Brasil, a oficialização do casamento religioso, no período colonial, e, mais tarde, a oficialização civil do matrimônio, no período republicano, alçavam essas famílias a um status superior. Casais que vivessem uniões conjugais não legalizadas, chamadas concubinatos ou mancebias, sempre estiveram à margem social, o que tornaria mais fácil para a mulher fazer a denúncia, visto não ter, de qualquer modo, uma "imagem a zelar". Os próprios termos amigados, amasiados já são portadores de um juízo de valor negativo (SILVA, 2010).

Quanto à religião, foram as evangélicas que mais procuram o serviço. Esse dado é o mesmo encontrado em pesquisa de Fiorotti et al. (2018). As católicas representaram 40\% da amostra. Já as que se declararam seguidoras do Espiritismo foram as que menos procuraram os serviços do CRAM, seguidas das que se declararam sem religião.

A violência sexual por meio de relações sexuais forçadas atingiu $45 \%$ das mulheres. É importante que elas considerem esse fato como uma violência, porque 
demonstra que estão rompendo com a ideia da subalternidade feminina quando se trata de satisfazer aos desejos sexuais masculinos. Segundo Bozon (2004), a crença de que os homens têm maior pulsão sexual contribui para que as mulheres aceitem muitos comportamentos abusivos.

Um dado que merece ser destacado é que $45 \%$ da amostra afirmou não se considerar feminista, evidenciando o desconhecimento da importância do Feminismo como movimento de luta contra toda forma de opressão e injustiças de gênero. Ressalte-se que, nos anos 6o, na segunda onda do feminismo, a pauta de denúncia das feministas foi justamente a violência conjugal e doméstica. $O$ enfrentamento de toda forma de violação de direitos das mulheres segue sendo o tema aglutinador das diferentes tendências dos feminismos contemporâneos (HOLLANDA, 2018). Graças ao Movimento Feminista e dos grupos de mulheres é que se pode comemorar a existência de órgãos que, como o CRAM e as Delegacias Especializadas de Atendimento às Mulheres (DEAM's), formam uma rede de proteção e amparo às mulheres em situação de violência.

Os CRAS e os CREAS são responsáveis pelo atendimento das famílias em situação de vulnerabilidade, contando com apoio de uma equipe multidisciplinar. As famílias recebem suporte para vencer situações adversas, como, por exemplo, a violência doméstica (NEVES et al., 2019). Trata-se de conquistas que estão relacionadas 'às lutas das mulheres e que não podem ser menosprezadas.

Outra evidência trazida pela pesquisa empírica foi a predominância da violência psicológica, seguida das formas emocional e moral. Xingamentos, seguidos de socos, tapas, murros, bem como agressões sexuais e violações patrimoniais foram as formas prevalentes de violência descritas pelas integrantes do estudo. Quanto ao que seja um ato de violência, percebeu-se que as mulheres a identificam com clareza e abrangência. Perguntadas "O que você considera violência?” as respostas foram: “Todo tipo de agressão física ou psicológica, relação abusiva onde você vive a mercê da vontade do parceiro"; "Todo tipo de forma de denegrir a imagem do outro"; "Violência é qualquer tipo de ação que me fere ou que me deixe constrangida, que me obrigue a algo ou que tire meu direito de ir e vir"; "Agressões físicas, xingamentos, destruir os objetos pessoais" e "Violência é apanhar, ser xingada, humilhada, maltratada".

Diante da pergunta "Quais saídas você acredita serem úteis para as mulheres que já sofreram e/ou sofrem violência?” $20 \%$ das entrevistadas citaram o apoio social e a sensação de não estarem sozinhas como elementos potencialmente importantes. Entre essas, uma enalteceu a importância das políticas públicas. A realização de denúncia junto às instâncias do poder judiciário foi citada por $16 \%$ das mulheres como um fator de extrema importância para o enfrentamento da violência. Também foram mencionados o afastamento do agressor e o autoconhecimento. Cinco usuárias não responderam a esse questionamento.

Algumas respostas, no entanto, deram sinal de impotência frente à violência, demonstrando descrédito na proteção policial e até mesmo na ineficiência da separação conjugal. Um exemplo são: "Acredito que a polícia demora muito para 
ajudar pessoas como nós. Pois muitas vezes chamava polícia e a polícia não aparecia" e "Não sei quais as saídas, porque se denunciar parece que a perseguição continua, pois a lei não consegue conter o agressor”. Há, ainda, como agravante ao descrédito, a consciência de que a separação é uma faca de dois gumes: "Separação às vezes só aumenta a maldade do agressor, mas ainda é o melhor meio de se sobressair".

As respostas de natureza aberta possibilitam adentrar no terreno fértil das representações que as mulheres possuem sobre um tema tão complexo quanto o da violência. Representações sociais, conceito transdisciplinar, se referem à maneira como os indivíduos interpretam o mundo e "leem" a vida cotidiana: "uma forma de conhecimento de atividade mental desenvolvida pelos indivíduos e pelos grupos para fixar suas posições em relações a situações, eventos, objetos e comunicações que lhes concernem (SÊGA, 200o).

Pensar que as representações não são mera opinião, mas uma forma de pensar o mundo a partir da relação entre sujeito e sociedade, permite compreender melhor porque as mulheres desse estudo, que afirmam não se identificar com o feminismo, defendem que a violência não é apenas agressões ao corpo físico, mas também se materializa em ofensas verbais. Ou seja, não é preciso ser feminista para pensar "feministicamente", porque esse pensamento sobre os direitos das mulheres é uma representação que está no ar, circula nas novelas, nas revistas de banalidades e nas músicas. Esse "refinamento civilizatório", que se tornou hoje uma representação bastante consensual, ainda que teoricamente, advém, na verdade, da luta de mulheres que ousaram pensar e agir além do que era permitido nos seus tempos.

O conceito de representação teve início com os estudos durkheinianos, mas foi com Moscovici (2011) que ganharam maior amplitude. Em La Psychanalyse: son image et son public, obra publicada em 1961, Moscovici, destacou como a psicanálise era compreendida e ressignificada à medida que transitava de um grupo para outro da sociedade, ganhando novos significados. Segundo o autor, as representações sociais são o resultado de um contínuo processo de ressignificação, levando ao entendimento de que ninguém constrói ideias sozinho. Por serem circulantes, os conhecimentos se cruzam, gerando novos conceitos/representações e também comportamentos/ práticas. Por isso, para Moscovici a compreensão das representações sociais exige sempre o entendimento do contexto histórico em que elas se formam, entendendo-as como estruturas dinâmicas, resultado de dois processos que chamou de ancoragem e objetificação.

A ancoragem consiste em transformar o novo em algo familiar, por meio de modelos já estocados em nossa memória enquanto a objetificação é o processo que transforma noções abstratas em algo concreto e quase tangível no mundo físico, classificando e nomeando, já que dar nome a alguma coisa é inseri-la numa matriz de cultura (MOSCOVICI, 2011).

Por isso, Sêga (200o, p. 132) afirma que as representações sociais nascem "no curso das variadas transformações que geram novos conteúdos", quando ocorre uma metamorfose em que as coisas não apenas se modificam, mas passam a ser vistas de outra forma e com maior clareza. Entretanto, a mudança nas representações não 
corresponde, necessariamente, à quebra de preconceitos e estereótipos, pois esses, à despeito das ideias novas, continuam existindo.

Nesse aspecto, pode-se dizer que o entendimento do que seja a violência contra as mulheres, nos últimos tempos, adquire novos significados e estes são bastante distanciados das representações elaboradas por mulheres, e também por homens, de cinco ou seis décadas atrás, ainda que isso não implique que ela tenha deixado de existir. Importa, ainda, afirmar que as representações sobre o que seja a violência não é exatamente "a violência" em sua concretude, mas a interpretação da violência mediada pelas experiências subjetivas de cada indivíduo.

A partir das respostas obtidas não foi possível ter segurança quanto à raça das entrevistadas. Considera-se que essa é uma fragilidade da presente pesquisa, notadamente levando-se em conta que, na atualidade, as discussões sobre as experiências femininas são sempre perpassadas pelas interseccionalidades. Dessa forma, pensar o gênero articulado com outras formas de opressão, consiste hoje na maior força dos feminismos contemporâneos (HOOKS, 2019). O fato de que, no Brasil, assim como em outros países da América Latina, as mulheres negras sejam aquelas que mais sofrem a violência de gênero (GIANNINI \& COELHO, 2020), transforma o racismo num problema crucial para se pensar políticas emancipatórias.

Do mesmo modo, não se incluiu nos questionários questões versando especificamente sobre as consequências da violência sobre saúde das mulheres, mas hoje é largamente aceito que violência praticada por parceiros íntimos compromete a saúde das mulheres.

Em 1996, a 49a․ Assembleia Mundial de Saúde declarou a violência como um problema importante, e crescente, de saúde pública no mundo. Essa tomada de consciência foi influenciada, entre outras coisas, pela IV Conferência Mundial sobre a Mulher, em Beijing, cujo tema central foi "Ação para a Igualdade, o Desenvolvimento e a Paz". Nela, reafirmou-se os direitos das mulheres como direitos humanos e o comprometimento com ações específicas para garantir o respeito a esses direitos (MINAYO et al., 2018).

Em 2002, a Organização Mundial da Saúde reconheceu que mulheres em situação de violência estão mais predispostas ao adoecimento, passam por mais cirurgias, consultas médicas, internações, idas a farmácias e consultas de saúde mental (WHO, 2005). A violência provoca traumas físicos e mentais e diminui a qualidade de vida das mulheres (MILLER \& MACWAN, 2019; CRUZ E IRFFI, 2019; MINAYO et al., 2018), estando associada a maiores índices de suicídios, uso abusivo de drogas, problemas ginecológicos diversos, maior vulnerabilidade ao HIV/ Aids, aborto, baixo peso de recém-nascido, síndrome do intestino irritável, dores musculares incapacitantes, fibromialgia, depressão, ansiedade, insônia e ideação suicida (SCHRAIBER, 2007). Além disso, pelo seu caráter crônico e constante, leva a vivências de desintegração, desamparo e medo (MANDELBAUM et al., 2016) e, mesmo após o rompimento com o agressor, as mulheres continuam com a qualidade de vida comprometida (MINAYO, 2018). 
A partir da evidência da inter-relação entre violência e adoecimento é dever do Estado implementar políticas públicas que mudem a estrutura social (LUCENA et al, 2017). No Brasil, em 2006, o governo lançou a Política Nacional de Promoção da Saúde (PNPS), enfatizando a necessidade de respeito às diferenças de gênero, a construção da cultura da paz e dos direitos humanos (BRASIL, 2018). Entende-se por promoção da saúde o processo que permite às pessoas maior controle sobre os determinantes da saúde, favorecendo a melhora de seu bem-estar e sua qualidade de vida. Trata-se de um processo social e político que prevê tanto atitudes isoladas dos indivíduos quanto tomadas de ações políticas direcionadas a mudanças das condições sociais, ambientais e econômicas (CHIESA et al., 2019).

Ao propor o enfrentamento da violência como um elemento promotor da cultura da paz, a PNPS não está se referindo exclusivamente à violência na perspectiva de gênero, mas a todo tipo de violência, tais como: comportamento suicida, violência interpessoal (da família ou do parceiro íntimo, comunitária); violência coletiva (social, política, econômica), etc.

Entre os objetivos da PNPS, destacam-se:

II- Contribuir para adoção de práticas sociais e de saúde centradas na equidade, na participação e no controle social, a fim de reduzir as desigualdades sistemáticas, injustas e evitáveis, respeitando as diferenças de classe social, de gênero, de orientação sexual e a identidade de gênero; entre gerações; étnico-raciais; culturais; territoriais; e relacionadas às pessoas com deficiências e necessidades especiais. IV- Promover a cultura da paz em comunidades, territórios e municípios (BRASIL, 2018, p. 11 - grifos das autoras).

A PNPS contempla seis temas transversais considerados referências para a formulação de agendas de promoção da saúde, entre os quais, no que diz respeito à violência destaca-se: Cultura da paz e direitos humanos. Na PNPS, a paz é entendida num sentido abrangente, não se tratando somente de oposição à guerra. O documento supracitado define a paz como "um fenômeno complexo que envolve a construção de uma estrutura e de relações sociais em que exista justiça, igualdade, respeito, liberdade e pela ausência de todo tipo de violência", relacionada "ao desenvolvimento, aos direitos humanos, à diversidade e à cooperação de pessoas, grupos ou nações" (BRASIL, 2018).

Considere-se, contudo, que a cultura da paz não pode ser entendida como uma conquista utópica. Ela exige dos governantes posicionamentos firmes de validação dos direitos das mulheres e desconstrução de modelos de masculinidade hegemônica capazes de ensejar mudanças nos valores patriarcais prevalentes na sociedade brasileira. Sem que se criem meninos que batam, jamais haverá mulheres que apanhem. Essa é uma realidade que não se pode mascarar. 


\section{Algumas considerações finais}

Frente aos dados apresentados, evidencia-se a urgência de estratégias de enfrentamento à violência de gênero a nível internacional, nacional e estadual. Considera-se que o enfrentamento do problema exige uma percepção clara acerca do que seja efetivamente um ato de violência de gênero, evitando digressões desnecessárias. É preciso ainda oportunizar às mulheres, que sofrem violências, condições de falar sobre suas experiências, a fim de que as políticas públicas contemplem efetivamente suas necessidades.

Por fim, é preciso que, na luta pelo enfrentamento à violência, essa seja entendida como sendo o resultado de discursos misóginos que circulam na sociedade, tanto quanto da falta de ações efetivas dos governantes; aliás, a maioria homens descompromissados com as demandas das mulheres. Isso para não mencionarmos as poucas mulheres que, chegando ao cargo máximo de seus países, não conseguem romper com os padrões de gênero prevalentes. De modo que, de nada adianta se insurgir contra a violência e, ao mesmo tempo, legitimar posicionamentos demolidores das conquistas árduas obtidas pelas feministas do passado.

As autoridades do Paraná, assim como a sociedade civil, precisam tomar medidas urgentes para que o estado deixe de apresentar os elevados índices de violência de gênero que o caracteriza. $O$ hino desse estado fala em rumores de felicidade, canções e flores pela estrada (Hino do Paraná, 2019). Que assim seja um dia.

\section{Referências}

ASSOCIAÇÃO BRASILEIRA DE EMPRESAS E PESQUISA - ABEP. Critério Brasil 2015 e atualização da distribuição de classes para 2016. Critério de Classificação Econômica Brasil, São Paulo. 2016. Disponível em: <www.abep.org>. Acesso em: 14 dez 2019.

ATLAS DA VIOLÊNCIA. Instituto de Pesquisa Econômica Aplicada. Governo Federal. 2019. Disponível em: <http://www.ipea.gov.br/portal/index.php?option=com_ content\&view=article\&id=34784\&Itemid=432>. Acesso em: $14 \mathrm{dez} 2019$.

BARDIN, Laurence. Análise de conteúdo. São Paulo, Edições 70. 2016.

BECCHERI-CORTEZ, Mirian \& SOUZA, Lídio de. Mulheres de classe média, relações de gênero e violência conjugal: um estudo exploratório. Revista Gestão e Políticas de Saúde. Bogotá (Colombia), 2013 n. 12, 24: p.34-53. Disponível em: <http://www.scielo. org.co/pdf/rgps/v12n24/v12n24ao3.pdfs. Acesso em: 10 mar 2020. 
BLAY, Eva. Como as mulheres se construíram como agentes políticas e democráticas: o caso brasileiro. In: BLAY, Eva \& AVELAS, Lucia. (orgs.). 50 Anos de feminismo: Argentina, Brasil e Chile. São Paulo: Editora da Universidade de São Paulo. 2019. p. 65-98.

BOZON, Michel. A nova normatividade das condutas sexuais ou a dificuldade de dar coerência às experiências íntimas. In: HEILBORN, Maria Luiza. (org.). Família e sexualidade. Rio de Janeiro: Editora FGV, 2004, p. 119-150.

BRASIL. Fórum Brasileiro de Segurança Pública. Anuário Brasileiro de Segurança Pública 2014 a 2017. ed. Especial. Brasília: Fórum Brasileiro de Segurança Pública. 2018. 143p. Disponível em: <http://www.forumseguranca.org.br/wp-content/ uploads/2018/o9/FBSP_ABSP_edicao_especial_estados_faccoes_2018.pdf>. Acesso em: 14 dez 2019.

BRASIL. Ministério da Saúde. Portaria de Consolidação n. 2, de 28 de setembro de 2017, que consolida as normas sobre as políticas nacionais de saúde do Sistema Único de Saúde. Brasília, Distrito Federal. 2017.

CHIESA, Anna Maria etal. Atenção à saúde na perspectiva da equidade. In: PELICIONI, Maria Cecília F. \& MIALHE, Fábio Luiz. (orgs.). Educação e Promoção da Saúde: teoria e prática. 2. ed. Rio de Janeiro: Santos, 2019, p. 289-296.

CONVENÇÃO Interamericana para prevenir, punir e erradicar a violência contra as Mulheres ‘Convenção de Belém do Pará’. Belém do Pará. 1994. Disponível em: <http:// www.cidh.org/Basicos/Portugues/m.Belem.do.Para.htm>. Acesso em: 14 dez 2019.

CRUZ, Mércia Santos \& IRFFI, Guilherme. Qual o efeito da violência contra a mulher brasileira na autopercepção da saúde?. Ciência E Saúde Coletiva. 2019, n. 24, 7: p.2531-2542, jan-jul. Disponível em: <http://www.scielo.br/scielo.php?script=sci_ arttext\&pid=S1413-81232019000702531>. Acesso em: 14 dez 2019.

FIOROTTI, Karina Fardin et al. Prevalência e fatores associados à violência doméstica: estudo em uma maternidade de alto risco. Texto $\mathcal{E}$ Contexto Enfermagem, 2018, n. 27, 3: p.eo810017, jul. Disponível em: <http://www.scielo.br/pdf/tce/v27n3/o104-0707tce-27-03-eo810017.pdf>. Acesso em: 14 dez 2019.

FREIRE, Ana Cláudia. Casos de violência doméstica aumentam quase $25 \%$ no Paraná em 2019. Paraná Portal. 2019. Disponível em: <https://paranaportal.uol.com.br/ cidades/violencia-domestica-aumenta-parana/>. Acesso em: 13 fev 2020.

GARCIA, Leilla Posenato \& DUARTE, Elisete. Intervenções não farmacológicas para o enfrentamento à epidemia da COVID-19 no Brasil. Epidemiol. Serv. Saúde, 
Brasília, 2020, n. 29, 2: p. e2020222. Disponível em: <http://www.scielo.br/scielo. php?script=sci_arttext\&pid=S2237-96222020000200100\&lng=en\&nrm=is $>$. Acesso em 28 abr 2020.

GIANNINI, Renata Avelar \& COELHO, Terine Husek. Evidências sobre violências e alternativas para mulheres e meninas no Brasil, na Colômbia e no México: tendências, desafios e caminhos para o futuro. Rio de Janeiro: Instituto Igarapé. 2020. 39p.

GOMES, Izabel Solyszko. Feminicídios: um longo debate. Revista Estudos Feministas, Florianópolis, 2018, n. 26, 2: p.e39651, jun. Disponível em: <http://www.scielo.br/ scielo.php?script=sci_arttext\&pid=S0104-026X2018000200201\&lng=en\&nrm=iso $>$. Acesso em: 15 fev 2020.

GOMES, Romeu et al. Gênero, direitos sexuais e suas implicações sobre a saúde. Ciência E Saúde Coletiva, 2018, n. 23, 6: jun. p.1997-2006. Disponível em: <http:// www.scielo.br/scielo.php?script=sci_abstract\&pid=S1413-81232018000601997\&lng=pt \&nrm=iso $>$. Acesso em: 02 nov 2019.

GONÇALVES, Eliane \& MELLO, Luiz. Apresentação: gênero - vicissitudes de uma categoria e seus 'problemas. Ciencia e Cultura, São Paulo, 2017, n. 69, 1: p.2630, mar. Disponível em: <http://cienciaecultura.bvs.br/scielo.php?script=sci arttext\&pid=Sooo9-67252017000100012\&lng=en\&nrm=iso >. Acesso em: 15 fev 2020.

HINO do Estado do Paraná. Wikipédia. Disponível em <https://pt.wikipedia.org/ wiki/Hino_do_Paran\%C3\%Ar>. Acesso em: 14 dez 2019.

HOLLANDA, Heloisa Buarque de. Falo eu, professora, 79 anos, mulher, branca e cisgênero. In: HOLLANDA, Heloisa Buarque de. Explosão feminista: arte, cultura, política e universidade. São Paulo: Companhia das Letras. 2018. p. 241-251.

HOOKS, Bell. O feminismo é para todo mundo: políticas arrebatadoras. Tradução de Ana Luiza Libâneo. Rio de Janeiro: Rosa dos Tempos. 2019. 175p.

LIMA, Camila Rodrigues Neves de Almeida. Gênero, trabalho e cidadania: função igual, tratamento salarial desigual. Revista Estudos Feministas, Florianópolis, 2018 n. 26, 3: p. e47164, out. Disponível em: <http://www.scielo.br/scielo.php?script=sci arttext\&pid=So104-026X2018000300210\&lng=pt\&nrm=iso $>$. Acesso em: 14 dez 2019.

LUCENA, Kerle Dayana Tavares et al. Association between domestic violence and women's quality of life. Revista Latino-Americana de Enfermagem, Ribeirão Preto, 2017, n. 25: p.e2901, jun. Disponível em: <http://www.scielo.br/scielo.php?script=sci_ arttext\&pid=So104-11692017000100348\&lng=en\&nrm=iso >. Acesso em: 14 dez 2019. 
MANDELBAUM, Belinda et al. Violência e vida familiar: abordagens psicanalíticas e de gênero. Saúde e Sociedade, São Paulo, 2016, n. 25, 2: p.422-430, jun. Disponível em: <http://www.scielo.br/scielo.php?script=sci_arttext\&pid=So10412902016000200422\&lng=en\&nrm=iso $>$. Acesso em: 14 dez 2019.

MILLER, Elizabeth \& MACWAN, Brigid. Intimate partner violence. The England Journal of Medicine, 2019, n. 380, 9: p.850-857, feb. Disponível em: <https://www. ncbi.nlm.nih.gov/pubmed/30811911>. Acesso em: 23 nov 2019.

MINAYO, Maria Cecília de Souza \& SCHENKER, Miriam. Complexidade da violência e impactos sobre a saúde. In: ASSIS, Simone Gonçalves de \& SILVEIRA, Liane Maria Braga da (orgs.). O tema da violência no ensino em saúde coletiva: articulações com pesquisa e extensão. Rio de Janeiro: E-Papers. 2018. 388p.

MINAYO, Maria Cecília de Souza et al. Institucionalização do tema da violência no SUS: avanços e desafios. Ciência E Saúde Coletiva, Rio de Janeiro, 2018, n. 23, 6: p.2007-2016, jun. Disponível em: <http://www.scielo.br/scielo.php?pid=S141381232018000602007\&script=sci_arttext\&tlng=pt>. Acesso em: 14 dez 2019.

MOSCOVICI, Serge. Representações Sociais: Investigações em Psicologia Social. Trad. Pedrinho A. Guareschi. 6a ed. Petrópolis: Vozes. 2011.

NEME, Cristina \& SOBRAL, Isabela. Principais resultados. In: Fórum Brasileiro de Segurança Pública. Visível e invisível: a vitimização de mulheres no Brasil. São Paulo: Instituto Data Folha. 2019. 5op.

NEVES, Luciana C. et al. Violência de gênero e a atuação da delegacia da mulher na Amazônia Paraense. Revista Ártemis, 2019, n. 28, 1: p.227-242, jul-dez.

PETERMAN, Amber. et al. Pandemics and violence against women and children. Working paper 528. Center for Global Development. Apr. 2020.

RICOLDI, Arlene \& ARTES, Amélia. Mulheres no ensino superior brasileiro: espaço garantido e novos desafios. Ex aequo, Lisboa, 2016 n. 33, p. 149-161, jun. Disponível em: $\quad<$ http://www.scielo.mec.pt/scielo.php?script=sci_arttext\&pid=So87455602016000100011\&lng=pt\&nrm=iso.> Acesso em: 14 jan 2020

SANTOS, Cristina Vianna Moreira dos \& IRINEU, Bruna Andrade. Violência contra mulheres e promoção de saúde mental na comunidade. Revista do NUFEN, Belém, 2019, n. 11, 1: p.232-245, abr. Disponível em: <http://pepsic.bvsalud.org/scielo. php?script=sci_arttext\&pid=S2175-25912019000100015>. Acesso em: 14 jan 2020. 
SÊGA, Rafael Augustus. O conceito de Representação Social nas obras de Denise Jodelet e Serge Moscovici. Revista do Programa de Pós-Graduação em História. Porto Alegre, 2000, v. 8, n. 13: p.128-133. Disponível em <https://seer.ufrgs.br/anos9o/article/ view/6719/4026>. Acesso em: 26 de abril 2020.

SCHRAIBER, Lilia Blima et al. Prevalência da violência contra a mulher por parceiro íntimo em regiões do Brasil. Revista de Saúde Pública, São Paulo, 2007, n. 41, 5: p.797-807, out. Disponível em: <http://www.scielo.br/scielo.php?script=sci_ arttext\&pid=So034-89102007000500014>. Acesso em: 14 dez 2019.

SCOTT, Joan. Gênero: uma categoria útil de análise histórica. Educação e Realidade, 1995, n. 20, 2: p.71-99. Disponível em: <https://seer.ufrgs.br/index.php/ educacaoerealidade/article/view/71721>. Acesso em: 14 dez 2019.

SILVA, Tania Maria Gomes da et al. Violence against women and commitment to health from the perspective of victims. International Journal of Development Research, 2019, n. 9, 8: p.29368-29370, Aug. Disponível em: <http://www.journalijdr.com/sites/ default/files/issue-pdf/16604.pdf>. Acesso em: 14 dez 2019.

SILVA, Tania Maria Gomes da. Não existe pecado ao sul do Equador: uniões consensuais nas camadas populares. Rio de Janeiro: Annablume. 2010. 154p.

VIEIRA, Adriane et al. Um estudo das relações entre gênero e âncoras de carreira. Cadernos EBAPE.BR, Rio de Janeiro, 2019, n. 17, 3: p.577-589, set. Disponível em: <http:// www.scielo.br/scielo.php?script=sci_arttext\&pid=S1679-39512019000300577\&lng=en \&nrm=iso >. Acesso em: 14 dez 2019.

VIEIRA, Pamela Rocha; GARCIA, Leila Posenato; MACIEL, Ethel Leonel Noia. Isolamento social e o aumento da violência doméstica: o que isso nos revela? Rev. Bras. Epidemiologia. 2020. 23. Disponível em: <https://blog.scielo.org/wp-content/ uploads/2020/04/1980-5497-rbepid-23-e200033.pdf>. Acesso em: 25 de mar 2020.

WORLD HEALTH ORGANIZATION. Multi-country study on women's health and domestic violence against women. Initial results on prevalence, health outcomes and women's responses. Geneva: WHO. 2005. Disponível em: <https://www. researchgate.net/profile/Lori_Heise/publication/288482508_Associations_ between_violence_by_intimate_partner_and_women's_sexual_and_reproductive_ health/links/5742f6coo8ae298602ee6572.pdf>. Acesso em: 14 jul 2018.

WORLD HEALTH ORGANIZATION. Global plan of action to strengthen the role of the health system within a national multisectoral response to address interpersonal violence, inparticularagainstwomenand girls, andagainstchildren.Switzerland.2016. Disponível em: <https://apps.who.int/iris/bitstream/handle/10665/252276/9789241511537-eng. 


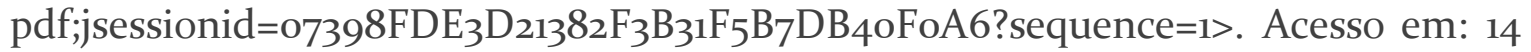
dez 2019.

WORLD HEALTH ORGANIZATION. WHO Director-General's opening remarks at the media briefing on COVID-19. Geneva. 2020. Disponível em: <https://www.who.int/ $\mathrm{dg} /$ speeches/detail/who-director-general-s-opening-remarks-atthe-media-briefingon-covid-19---20-april-2020>. Acesso em: o9 maio 2020.

Recebido em 28/04/2020.

Aceito em 19/05/2021. 